\title{
Closed and Open Grade I and II Tibial Shaft Fractures Treated by Reamed Intramedullary Nailing
}

\author{
Ali Djahangiri Raffaele Garofalo François Chevalley \\ Pierre-François Leyvraz Michael Wettstein Olivier Borens \\ Constantin Schizas Elyazid Mouhsine
}

Orthopedic and Traumatology Department, University Hospital of Lausanne, Lausanne, Switzerland

\section{Key Words}

Tibial shaft fracture $\cdot$ Intramedullary nail

\begin{abstract}
Objective: To evaluate the results of closed and open grade I and II tibial shaft fractures treated by reamed nail and unreamed nailing. Subjects and Methods: Between 1997 and 2000, 119 patients with tibial shaft fractures were treated with reamed tibial nails. Postoperatively 96 patients (70 closed and 26 grade I and II open fractures) were followed clinically and radiologically for up to 18 months. The nail was inserted either by patellar tendon splitting or by nonsplitting technique. The nail was inserted after overreaming by $1.5 \mathrm{~mm}$. Postoperatively, patients with isolated tibial fracture were mobilized by permitting partial weight bearing on the injured leg for 6 weeks. Patients with associated ankle fractures were allowed to walk with a Sarmiento cast. Results: Postoperatively, 6 (6.3\%) patients developed a compartment syndrome after surgery. In 48 (50\%) cases, dynamization of the nail was carried out after a mean period of 12 weeks for delayed union. Overall, a $90.6 \%$ union was obtained at a mean of 24 weeks without difference between closed or open fractures. Two (2.1\%) patients with an open grade II fracture developed a deep infection requiring treatment. A $9.4 \%$ rate of malunion was observed.
\end{abstract}

Eight (8.3\%) patients developed screw failure without clinical consequences. At the last follow-up, $52 \%$ of patients with patellar tendon splitting had anterior knee pain, compared to those (14\%) who did not have tendon splitting. Conclusion: Reamed intramedullary nail is a suitable implant in treating closed as well as grade I and Il open tibial shaft fractures.

Copyright $@ 2006$ S. Karger AG, Basel

\section{Introduction}

The treatment goal of tibial shaft fractures is to achieve union with correct alignment and restoration of normal knee and ankle mechanics as well as regaining early autonomous ambulation. This is achieved by either nonoperative treatment or by surgery, using reamed or unreamed intramedullary nailing, open reduction and internal fixation (ORIF), and external fixation [1-6]. Locking Grosse and Kempf (GK) intramedullary nail was introduced in 1974. It permits wider indications for tibia nailing to proximal and distal fractures and enables simultaneous treatment of unstable fractures in length and rotation to stabilize middle shaft fractures $[7,8]$.

Intramedullary nailing has gained wide acceptance in the management of both closed and open fractures of Gustilo types I and II, as well as IIIAs and IIIBs [9-12].

\section{KARGER}

Fax +4161306 1234

E-Mail karger@karger.ch

www.karger.com
(C) 2006 S. Karger AG, Basel

$1011-7571 / 06 / 0154-0293 \$ 23.50 / 0$

Accessible online at:

www.karger.com/mpp
Dr. Elyazid Mouhsine

OTR-BH 14, CHUV

$\mathrm{CH}-1011$ Lausanne (Switzerland)

Tel. +41 2131427 91, Fax +41213142974

E-Mail elyazid.mouhsine@hosr.hospvd.ch 
Table 1. Fractures graded according to the AO and Gustilo classification

\begin{tabular}{lrrrr}
\hline & AO type A & AO type B & AO type C & Total \\
\hline Closed & 46 & 14 & 10 & 70 \\
Gustilo I & 13 & 2 & 0 & 15 \\
Gustilo II & 5 & 2 & 4 & 11 \\
\hline Total & 64 & 18 & 14 & 96 \\
\hline
\end{tabular}

The advantage is that closed reduction and good union rate are achieved [5]. Reaming of the tibia allows the insertion of a large diameter nail, which confers more stability, allows much earlier weight bearing, limits the risks of material fractures and reduces the risks of a second operation $[13,14]$. This study evaluated the results of closed and open grade I and II tibial shaft fractures treated by GK type reamed intramedullary nailing and unreamed nailing.

\section{Materials and Methods}

Of all adult patients treated for closed or open fractures of the tibial shaft between 1997 and 2000, 96 met these study criteria. Those treated nonoperatively, with external fixator or by ORIF were excluded from analysis, as were those treated with a GK nail (Stryker Howmedica), had polytrauma or primary treatment with an external fixator. Some were lost to follow-up.

Clinical charts and X-ray films of the 96 patients (65 males and 31 females; average age 43.6 years, range 18-72, 64 AO type A fracture, 18 type B and 14 type C) were retrospectively evaluated. Forty patients were injured as a result of a fall or a twist. Thirty-two patients were involved in a motor vehicle accident as either a driver, a passenger or a pedestrian and 24 were sports injuries. These included 70 closed, 15 open grade I, and 11 open grade II tibial fractures (table 1).

Seventeen patients presented an associated ipsilateral ankle fracture (11 lateral malleolus, 3 medial malleolus and 3 bimalleolar). Five patients had a fracture line that reached down the pilon, requiring an osteosynthesis with an anteroposterior lag screw.

Open wounds were debrided and closed. Antibiotic prophylaxis was performed with cefuroxime $(1.5 \mathrm{~g}$ intravenously preoperatively, and $0.75 \mathrm{~g} 8 \mathrm{~h}$ postoperatively). The prophylaxis $(0.75 \mathrm{~g}$ of cefuroxime 8-hourly) was extended to $48 \mathrm{~h}$ for open fractures.

The nail entry site was done by splitting the patellar tendon in 67 cases and without splitting in 29 cases. The diameter of the inserted nail was 9, 10,11, and $12 \mathrm{~mm}$ in 16, 29, 45 and 6 cases, respectively. Eighty-nine nails were statically interlocked, and for the rest ( 7 cases, with a middle-third transverse fracture), the nail was locked with double distal interlocking screws. Of the 89 cases with a high tibial shaft fracture, 8 required a proximal anteroposterior screw.
Compartment pressure was measured when lower limb compartment syndrome was suspected (based on clinical symptoms: pain on passive stretching of the compartment or pain out of proportion to the injury). Fasciotomy was performed when there was a difference in compartment pressure and diastolic pressure, $\Delta \mathrm{P}=$ $<30 \mathrm{~mm} \mathrm{Hg}$.

After $48 \mathrm{~h}$, patients with an isolated tibial fracture started $20 \mathrm{~kg}$ partial weight bearing on the injured leg for 6 weeks. In cases with an associated ankle fracture, weight bearing under protection with a Sarmiento plaster was allowed. Postoperatively, patients were followed up clinically and radiologically for up to 18 months. Clinical examination entailed evaluation of the presence of anterior knee pain, fracture-related pain, neurological status, the step angle, and shortening of the leg. The length of time for resumption of normal activities was also noted.

Clinical charts and anteroposterior and lateral X-ray views of the injured leg were assessed blindly by an independent examiner. Union, delayed union or malunion and metalwork failure were noted. Fractures were considered clinically united when pain-free walking was possible. On the X-ray films, union was defined as bridging callus on two radiographic views with disappearance of the fracture line. The absence of union after 3 months was considered as delayed union. After 6 months, it was considered as pseudarthrosis. Malunion was defined as varus/valgus greater than $5^{\circ}$, and/or anteflexum/recurvatum angulation greater than $10^{\circ}$, and/or internal/external rotation greater than $10^{\circ}$ after union.

Union, nonunion, infection rates as well as the incidence of compartment syndrome were evaluated separately in closed and open fractures for any significant differences. The association between the presence of compartment syndrome, the elapsed time between trauma and surgery, and operation time itself were also noted. Lastly, the presence of anterior knee pain was evaluated with respect to entry point of the nail and if the nail was proud or seated.

Statistical analysis of all data was performed using Wilcoxon signed-rank test for independent samples, $\mathrm{p}=0.05$.

\section{Results}

Nine $(9.4 \%)$ patients with neurological symptoms after the operation recovered within 3 months: 6 of the 9 had limb compartment syndrome treated by fasciotomy and, the remaining 3 who did not have clinical symptoms of compartment syndrome presented with extensor hallucis longus weakness and hypoesthesias of the first web space.

Three cases out of the 6 with compartment syndrome had closed fracture and 3 had Gustilo grade I open fracture. None of these patients presented an associated ankle fracture. They were operated on average $24 \mathrm{~h}$ after admission (range 4-48 h) and the mean intervention time was 105 min (range 60-145 min).

Postoperative X-ray films showed 1 varus, 2 valgus, and 4 recurvatum deformities exceeding $10^{\circ}$. In 6 patients, a distraction greater than $2 \mathrm{~mm}$ at the fracture site 
Fig. 1. Images in a 44-year-old man who was involved in a car accident. Preoperative anteroposterior X-ray view (a), postoperative lateral X-ray view (b) and after healing (c, d).
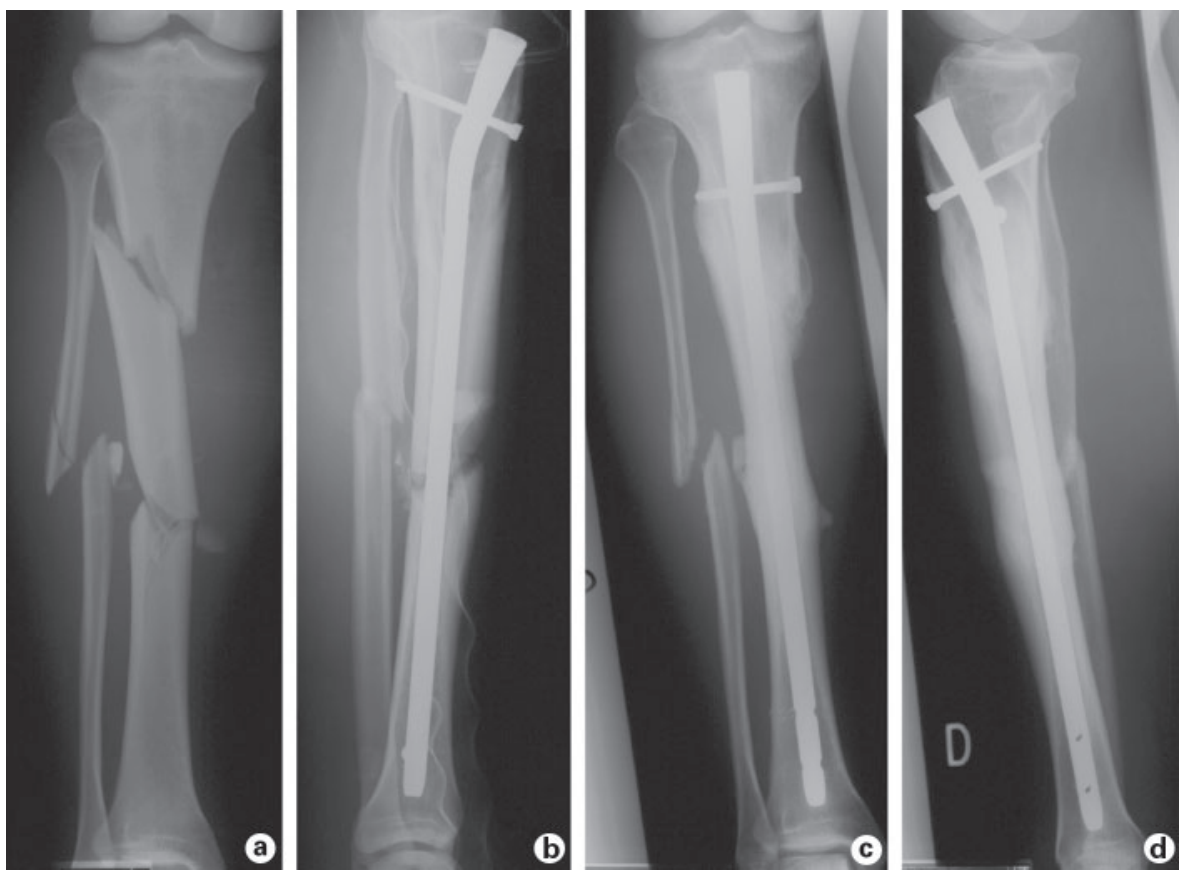

was observed. Five of these patients developed a compartment syndrome requiring fasciotomy.

Clinically, fracture union was observed on an average at 18 weeks (range 13-46) for both closed and open fractures, regardless of whether they were weight bearing or partial weight bearing (table 2). No statistically significant difference was found in union times between closed and open injuries ( $p>0.05)$. For compartment syndrome, no correlation was found between the time elapsed from accident to surgery or with operative time itself $(p=>0.05)$. A strong correlation was noted between compartment syndrome and fracture distraction after reduction $(\mathrm{p}=$ $<0.05)$.

In $48(50 \%)$ cases, delayed union requiring dynamization at 12 weeks on average was found. Union after dynamization was observed on average after 6 weeks (range 4-10 weeks, fig. 1).

Nonunion occurred in $5(5 \%)$ patients. Three of these 5 patients had a closed fracture and the other 2 an open grade II fracture (fig. 2). Treatment for nonunion consisted in 2 cases of bone grafting, in 2 cases of exchange nailing and in 1 of nail removal with application of a walking cast. Two (2.1\%) patients, both grade II open fractures, developed a deep infection. Treatment consisted of administration of antibiotics, nail removal and plaster until healing.
Table 2. Union time in weeks

\begin{tabular}{|c|c|c|}
\hline & $\begin{array}{l}\text { Partial weight bearing } \\
(\mathrm{n}=79)\end{array}$ & $\begin{array}{l}\text { Sarmiento plaster } \\
(\mathrm{n}=17)\end{array}$ \\
\hline $\begin{array}{l}\text { Closed } \\
(\mathrm{n}=70)\end{array}$ & $\begin{array}{l}(\mathrm{n}=52) \\
24(13-36 \pm 5.8)\end{array}$ & $\begin{array}{l}(n=14) \\
23(13-35 \pm 6.7)\end{array}$ \\
\hline $\begin{array}{l}\text { Open I and II } \\
(\mathrm{n}=26)\end{array}$ & $\begin{array}{l}(\mathrm{n}=27) \\
24(13-46 \pm 9.8)\end{array}$ & $\begin{array}{l}(\mathrm{n}=3) \\
26(18-39 \pm 10.6)\end{array}$ \\
\hline
\end{tabular}

No significant differences were found between closed and open fracture or whether treatment was partial or full weight bearing.

Statistically, no significant difference was observed between closed and open fractures with both compartment syndrome and delayed union $(\mathrm{p}=>0.05)$. However, a statistically significant correlation was observed between open fractures and infection $(\mathrm{p}<0.05)$.

Eight $(8.3 \%)$ patients had implant failure: 4 proximal and 4 distal screw breakages. In 6 of these 8 patients, the fracture was overdistracted, but all progressed to bony union. At the last follow-up, 27 patients had difficulties due to fracture repair: $2(2.1 \%)$ neurological symptoms and $5(5.2 \%)$ occasional fracture-related pain. Fifteen $(15.6 \%)$ had ankle pain but only 5 of them had an operated ankle fracture. 
Fig. 2. Images in a 50-year-old man who fell from a 6-meter height. Preoperative anteroposterior X-ray view (a), postoperative lateral X-ray view (b) and pseudarthrosis (c).
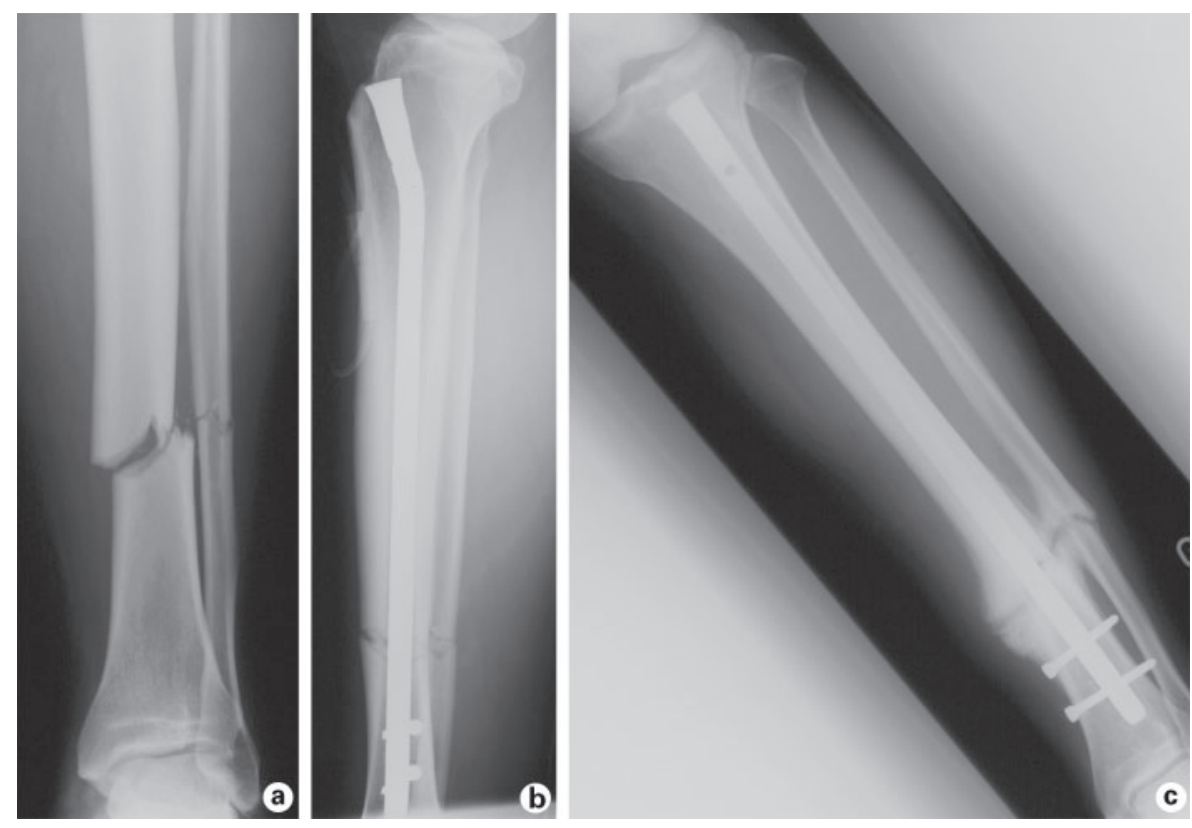

Thirty-nine $(41 \%)$ patients complained of anterior knee pain. Analysis of the results showed that $52 \%$ of patients who were nailed by splitting the patellar tendon presented anterior knee pain and only 14\% complained of knee pain when the tendon had not been split, irrespective of weather the nail was proud or well seated. This difference was statistically significant $(\mathrm{p}<0.05)$. For 9 $(9.4 \%)$ patients, the fractures healed with malunion: 2 in varus of 8 and $10^{\circ}$, respectively, 5 in valgus of $8^{\circ}$ on average (range $7-10^{\circ}$ ) and 2 external rotation malalignment with a step angle discrepancy of $10^{\circ}$. All malunions were asymptomatic. No anterecurvatum deformity and leg shortening occurred.

All patients, excluding office workers, resumed work 5 months (range: 3-15) after injury. Sporting activities were possible at 6.5 months (range: $3-18$ ).

\section{Discussion}

In this study, a combined union rate of $90.6 \%$ was noted for closed and open grade I and II tibial fractures treated by intramedullary reamed nailing. These findings are comparable with others, for both reamed and unreamed nailing $[9,15]$.

Time to complete union as confirmed by radiological union was 4 weeks longer compared to the published union times $[1,16,17]$. Possibly, this difference could be due to interobserver variability in X-ray film evaluation [18] and the definition of union. However, clinically judged union time (as observed on average 6 weeks prior to radiological union) compared favorably with previously reported data $[1,16,17]$.

The $8.3 \%$ screw breakage rate compares favorably with other studies on unreamed nailing [11, 13, 15]. The strength of intramedullary nails is primarily determined by their diameter. This is also true for interlocking screws. Therefore, larger nails are stronger and more resistant to failure than smaller unreamed nails and these confer increased stability of the fracture site [14]. The nonunion rate in this study was similar to that reported in the literature $[2,17,19]$ and no difference was noted in nonunion rates between closed and open fractures. However, Bhandari et al. [15] showed that reamed nailing reduced the risk of nonunion by $57 \%$, irrespective of whether the fracture was closed or open. Although several biological studies have shown a negative effect of reaming on intramedullary blood flow [20], others have demonstrated that this does not influence callus formation [9, 15, 21, 22].

The malunion rate of $9.4 \%$ in this study is similar to that reported earlier [23]. That our rotational malalignment patients ( 2 cases) were asymptomatic, is in agreement with the observation that deformities less than $15^{\circ}$ tend to produce little symptoms [24, 25].

The cases with compartment syndrome (6 patients) in the current study were linked to intraoperative overdis- 
traction with no association with delay in surgery time. These findings are in accordance with published data [26]. Although it has been suggested that reaming tends to increase the risk of compartment syndrome, the converse has also been shown in a study involving compartment pressure measures before, during and after surgery [27].

McQueen et al. [26] reported good functional outcome for patients who had decompression within $24 \mathrm{~h}$. In this study, it is interesting to note that postoperatively 3 patients with a closed fracture presented a dropped hallux with hypoesthesias of the first interdigital space without any confirmation of compartment syndrome. All experienced spontaneous resolution within 6 months, as was reported previously [28]. We hypothesized that a branch of the deep peroneal nerve was damaged during proximal interlocking even though it was performed from medial to lateral. However, a compartment syndrome with a mild clinical course or a distraction of the nerve due to the position on the orthopedic table cannot be excluded.

The two deep infections occurred in grade II open fractures. This low rate may be due to aggressive débridement and the associated use of intravenous antibiotics. Compared to other studies on reamed and unreamed nailing, this result suggests that reaming does not increase the infection rate even though ours was not a randomized trial $[2,9,5,23]$. Recent reports showed no difference in infection rates in open fractures, regardless of whether they were treated with reamed or unreamed nailing $[9,13,17]$. However, infection rates can rise to $18 \%$ when grade IIIB open fractures are nailed after reaming [10].

The incidence of anterior knee pain (41\%) in this current study compares favorably with that reported previously [29]. However, a statistical difference was found for knee pain in relation to the surgical technique (tendon splitting vs. no splitting) employed, $\mathrm{p}<0.05$. A large group of patients would be necessary to validate the findings here regarding anterior knee pain.

\section{Conclusion}

Reamed intramedullary nailing is an effective measure in treating closed and grade I and II open tibial fractures. Reaming permitted the insertion of stronger nail, which decreased material failure and increased fracture site stability. The incidence of anterior knee pain suggests avoiding patellar tendon splitting.

\section{References}

1 Bone LB, Sucato D, Stegemann PM, Rohrbacher BJ: Displaced isolated fractures of the tibial shaft treated with either a cast or intramedullary nailing: an outcome analysis of matched pairs of patients. J Bone Joint Surg Am 1997; 79:1336-1341.

$>2$ Karladani AH, Granhed H, Edshage B, Jerre $\mathrm{R}$, Styf J: Displaced tibial shaft fractures: a prospective randomized study of closed intramedullary nailing versus cast treatment in 53 patients. Acta Orthop Scand 2000;71:160-167.

$>3$ Littenberg B, Weinstein LP, McCarren M, Mead T, Swiontkowski MF, Rudicel SA, Heck D: Closed fractures of the tibial shaft: a metaanalysis of three methods of treatment. J Bone Joint Surg Am 1998;80:174-183.

4 Sarmiento A: On the behavior of closed tibial fractures: clinical/radiological correlations. J Orthop Trauma 2000;14:199-205.

5 Suter M, Blanc C-H, Chevalley F: Enclouage verrouillé du tibia. Swiss Surg 1995;1:250_ 255.

-6 Toivanen JA, Honkonen SE, Koivisto AM, Jarvinen MJ: Treatment of low-energy tibial shaft fractures: plaster cast compared with intramedullary nailing. Int Orthop 2001;25: $110-113$.

Tibial Shaft Fractures, Reamed Intramedullary Nailing
7 Kempf I, Grosse A, Taglang G, Bernhard L, Moui Y: L'enclouage centro-médullaire avec verrouillage dans les fractures récentes du fémur et du tibia. Chirurgie 1991;117:478487.

$>8$ Templeman D, Larson C, Varecka T, Kyle RF: Decision making errors in the use of interlocking tibial nails. Clin Orthop Relat Res 1997; 65-70.

>9 Finkemeier CG, Schmidt AH, Kyle RF, Templeman DC: A prospective, randomized study of intramedullary nails inserted with and without reaming for the treatment of open and closed fractures of the tibial shaft. J Orthop Trauma 2000; 14:187-193.

10 Keating JF, Blachut PA, O'Brien PJ, CourtBrown CM: Reamed nailing of Gustilo gradeIIIB tibial fractures. J Bone Joint Surg Br 2000; 82:1113-1116.

11 Keating JF, O’Brien PJ, Blachut PA, Meek RN, Broekhuyse HM: Locking intramedullary nailing with and without reaming for open fractures of the tibial shaft: a prospective, randomized study. J Bone Joint Surg Am 1997;79 334-341.

12 Tropet Y, Garbuio P, Obert L, Ridoux PE: Emergency management of type $3 \mathrm{~B}$ open tibial fractures. Br J Plast Surg 2001;52:462-470.
13 Bhandari M, Guyatt GH, Swiontkowski MF, Schemitsch EH: Treatment of open fractures of the shaft of the tibia. J Bone Joint Surg Br 2001;83:62-68.

14 Ruiz AL, Kealey WD, McCoy GF: Implant failure in tibial nailing. Injury 2000;31:359362 .

15 Bhandari M, Guyatt GH, Tong D, Adili A, Shaughnessy SG: Reamed versus nonreamed intramedullary nailing of lower extremity long bone fractures: a systematic overview and meta-analysis. J Orthop Trauma 2000;14:29.

16 Bhandari M, Tometta P, Sprague S, Najibi S, Petrisor B, Griffith L, Guyatt G: Predictors of reoperation following operative management of fractures of the tibial shaft. J Orthop Trauma 2003; 17:353-361.

17 Keating JF, O’Brien PI, Meek RN, Broekhuyse HM: Reamed interlocking intramedullary nailing of open fractures of the tibia. Clin Orthop Relat Res 1997;182-191.

18 Whelan DB, Bhandari M, McKee MD, Guyatt GH, Kreder HJ, Stephen D, Schemitsch EH: Interobserver and intraobserver variation in the assessment of the healing of tibial fractures after intramedullary fixation. J Bone Joint Surg Br 2002;84:15-18. 
19 Wiss DA, Stetson WB: Unstable fractures of the tibia treated with a reamed intramedullary interlocking nail. Clin Orthop Relat Res 1995; 56-63.

-20 Markmiller M, Tjarksen M, Mayr E, Ruter A: The unreamed tibia nail: multicenter study of the AO/ASIF. Osteosynthesefragen/Association for the Study of Internal Fixation. Langenbecks Arch Surg 2000;385:276-283.

$\checkmark 21$ Hupel TM, Weinberg JA, Aksenov SA, Schemitsch EH: Effect of unreamed, limited reamed, and standard reamed intramedullary nailing on cortical bone porosity and new bone formation. J Orthop Trauma 2001;15:18-27.

-22 Lindstrom T, Gullichsen E, Lertola K, Niinikoski J: Leg tissue perfusion in simple tibial shaft fractures treated with unreamed and reamed nailing. J Trauma 1997;43:636-639.
23 Coles CP, Gross M: Closed tibial shaft fractures: management and treatment complications. A review of the prospective literature. Can J Surg 2000;43:256-262.

24 Bonnevialle P, Andrieu S, Bellumore Y, Challe JJ, Rongieres M, Mansat M: Torsional abnormalities and length discrepancies after intramedullary nailing for femoral and tibial diaphyseal fracture: computerized tomography evaluation of 189 fractures. Rev Chir Orthop Réparatrice Appar Mot 1998;84:397410.

25 Strecker W, Hoellen I, Keppler P, Suger G, Kinzl L: Correcting torsion after intramedullary nailing osteosynthesis of the lower extremity. Unfallchirurg 1997;100:29-38.
26 McQueen MM, Christie J, Court-Brown CM: Compartment pressures after intramedullary nailing of the tibia. J Bone Joint Surg Br 1990; 72:395-397.

27 Nassif JM, Gorczyca JT, Cole JK, Pugh KJ, Pienkowski D: Effect of acute reamed versus unreamed intramedullary nailing on compartment pressure when treating closed tibial shaft fractures: a randomized prospective study. J Orthop Trauma 2000;14:554-558.

28 Robinson CM, O’Donnel J, Will E, Keating JF: Dropped hallux after the intramedullary nailing of tibial fractures. J Bone Joint Surg Br 1999;81:481-484.

29 Court-Brown CM, Gustilo T, Shaw AD: Knee pain after intramedullary tibial nailing: its incidence, etiology, and outcome. J Orthop Trauma 1997;11:103-105. 